\title{
Hyperphosphatemia and risks of acute kidney injury, end-stage renal disease, and mortality in hospitalized patients
}

Hongran Moon ${ }^{1}$, Ho Jun Chin ${ }^{1,2}$, Ki Young Na ${ }^{1,2}$, Kwon Wook Joo', Yon Su Kim', Sejoong Kim ${ }^{1,2^{*}}$ and Seung Seok $\operatorname{Han}^{1 *}$ (D)

\begin{abstract}
Background: Hyperphosphatemia is associated with vascular calcification and bone mineral disorders and is a major concern among patients with chronic kidney disease (CKD). However, the relationship between hyperphosphatemia and renal outcome in non-CKD patients has not been studied. Furthermore, the clinical implications of hyperphosphatemia in relation to the risks of acute kidney injury (AKI), end-stage renal disease (ESRD), and mortality after hospitalization remain unresolved.

Methods: A total of 20,686 patients (aged $\geq 18$ years) admitted to Seoul National University Bundang Hospital from January 2013 to December 2013 were retrospectively reviewed. Patients were divided into quartiles according to serum phosphorus level at the time of admission. The odds ratios (ORs) for AKI and hazard ratios (HRs) for ESRD and allcause mortality were calculated after adjustment of multiple covariates.

Results: AKI developed in 2319 patients (11.2\%), with higher ORs for patients in the third and fourth quartiles (1.4 [1.24-1.68] and 2.8 [2.44-3.22], respectively) compared with the first quartile group. During a median follow-up period of 4.0 years, 183 patients (0.88\%) developed ESRD and 3675 patients (17.8\%) died. Patients in the fourth quartile had higher risks of ESRD and mortality than patients in the first quartile (HRs, 2.3 [1.46-3.75] and 1.4 [1.22-1.49], respectively). These trends remained consistent in patients with an estimated glomerular filtration rate $>60 \mathrm{ml} / \mathrm{min} /$ $1.73 \mathrm{~m}^{2}$.

Conclusions: Hyperphosphatemia is related to the risks of AKI, ESRD, and mortality, and it may therefore be necessary to monitor serum phosphorus level in hospitalized patients, irrespective of kidney function.
\end{abstract}

Keywords: Acute kidney injury, End-stage renal disease, Hyperphosphatemia, Mortality, Phosphorus

\section{Background}

Chronic kidney disease (CKD) is increasingly recognized as a public health problem [1] and is associated with higher risks of cardiovascular disease and other conditions, including infections and cancer [2]. Acute kidney injury (AKI) is a renal complication that occurs in up to $20 \%$ of hospital admissions [3, 4], and which can eventually progression to CKD. Both AKI and CKD thus represent significant health burdens with potentially high morbidity and mortality rates [5].

\footnotetext{
* Correspondence: sejoong@snubh.org; hansway80@gmail.com ${ }^{1}$ Department of Internal Medicine, Seoul National University College of Medicine, 103 Daehakro, Jongno-gu, Seoul 03080, Korea Full list of author information is available at the end of the article
}

Serum phosphorus levels are regulated by multiple organs including the kidney, bone, and digestive systems [6]. Given that the kidney plays a major role in phosphorus regulation, phosphorus homeostasis can be disrupted in patients with kidney disease. Abnormal phosphorus levels may in turn be related to several morbidities, such as vascular calcification, mineral bone disease, and hyperparathyroidism $[7,8]$. Furthermore, the risk of death has been shown to increase by approximately $20 \%$ for each $1 \mathrm{mg} / \mathrm{dl}$ increment in serum phosphorus among patients with CKD $[9,10]$. Accordingly, the Kidney Disease Improving Global Outcomes (KDIGO) guidelines recommend monitoring serum phosphorus levels and lowering elevated levels towards the normal range in patients with CKD

(c) The Author(s). 2019 Open Access This article is distributed under the terms of the Creative Commons Attribution 4.0 International License (http://creativecommons.org/licenses/by/4.0/), which permits unrestricted use, distribution, and 
Table 1 Baseline characteristics of study participants

\begin{tabular}{|c|c|c|c|c|c|c|}
\hline \multirow[b]{2}{*}{ Variables } & \multirow[b]{2}{*}{$\begin{array}{l}\text { Total } \\
(n=20,686)\end{array}$} & \multicolumn{4}{|c|}{ Serum phosphorus level } & \multirow[b]{2}{*}{$P$} \\
\hline & & $\begin{array}{l}\text { 1st quartile } \\
(n=5660)\end{array}$ & $\begin{array}{l}\text { 2nd quartile } \\
(n=5717)\end{array}$ & $\begin{array}{l}\text { 3rd quartile } \\
(n=4487)\end{array}$ & $\begin{array}{l}\text { 4th quartile } \\
(n=4822)\end{array}$ & \\
\hline Age (years) & $58.9 \pm 17.0$ & $61.4 \pm 16.1$ & $59.5 \pm 16.7^{\ddagger}$ & $57.6 \pm 17.1^{\ddagger}$ & $56.5 \pm 18.1^{\ddagger}$ & $<0.001$ \\
\hline Male sex (\%) & 52.5 & 57.4 & 55.2 & $50.6^{\ddagger}$ & $46.1^{\ddagger}$ & $<0.001$ \\
\hline Body mass index $\left(\mathrm{kg} / \mathrm{m}^{2}\right)$ & $23.7 \pm 3.7$ & $23.6 \pm 3.7$ & $23.8 \pm 3.6$ & $23.7 \pm 3.6^{*}$ & $23.9 \pm 3.9^{\dagger}$ & 0.002 \\
\hline \multicolumn{7}{|l|}{ Comorbidities (\%) } \\
\hline Hypertension & 19.0 & 17.9 & 18.6 & 18.4 & $21.5^{\ddagger}$ & $<0.001$ \\
\hline Diabetes mellitus & 21.9 & 22.5 & 20.8 & $19.7^{\dagger}$ & 24.5 & $<0.001$ \\
\hline History of cardiovascular disease & 6.1 & 5.8 & 6.3 & 6.7 & 5.8 & 0.164 \\
\hline Chronic kidney disease & 8.0 & 8.7 & $7.0^{*}$ & $7.0^{*}$ & 9.4 & $<0.001$ \\
\hline \multicolumn{7}{|l|}{ Medications (\%) } \\
\hline ACEi & 1.4 & 1.1 & 1.3 & 1.6 & 1.6 & 0.180 \\
\hline ARB & 6.4 & 5.9 & 6.2 & 6.4 & $7.2^{*}$ & 0.040 \\
\hline Beta blocker & 5.9 & 4.5 & $6.1^{+}$ & $6.2^{\dagger}$ & $7.1^{\ddagger}$ & $<0.001$ \\
\hline Calcium channel blocker & 7.1 & 6.7 & 6.9 & 7.2 & $7.7^{*}$ & 0.193 \\
\hline Diuretics & 5.3 & 5.2 & 4.9 & 4.6 & $6.4^{+}$ & 0.001 \\
\hline \multicolumn{7}{|l|}{ Laboratory findings } \\
\hline Hemoglobin (g/dL) & $12.6 \pm 2.1$ & $12.3 \pm 2.2$ & $12.8 \pm 2.0^{\ddagger}$ & $12.9 \pm 2.0^{\ddagger}$ & $12.7 \pm 2.2^{\ddagger}$ & $<0.001$ \\
\hline Albumin (g/dL) & $3.9 \pm 0.6$ & $3.7 \pm 0.6$ & $4.0 \pm 0.6^{\ddagger}$ & $4.0 \pm 0.5^{\ddagger}$ & $4.0 \pm 0.6^{\ddagger}$ & $<0.001$ \\
\hline Total cholesterol (mg/dL) & $170.1 \pm 47.5$ & $157.3 \pm 46.4$ & $171.2 \pm 43.8^{\ddagger}$ & $177.5 \pm 47.3^{\ddagger}$ & $177.2 \pm 50.0^{\ddagger}$ & $<0.001$ \\
\hline Calcium (mg/dL) & $8.6 \pm 0.7$ & $8.3 \pm 0.7$ & $8.7 \pm 0.6^{\ddagger}$ & $8.8 \pm 0.5^{\ddagger}$ & $8.8 \pm 0.7^{\ddagger}$ & $<0.001$ \\
\hline Phosphorus (mg/dL) & $3.38 \pm 0.81$ & $2.46 \pm 0.41^{\ddagger}$ & $3.21 \pm 0.14^{\ddagger}$ & $3.64 \pm 0.11^{\ddagger}$ & $4.38 \pm 0.73^{\ddagger}$ & $<0.001$ \\
\hline Creatinine (mg/dL) & $0.82 \pm 0.72$ & $0.77 \pm 0.42$ & $0.76 \pm 0.57$ & $0.77 \pm 0.44$ & $1.00 \pm 1.28^{\ddagger}$ & $<0.001$ \\
\hline eGFR $\left(\mathrm{mL} / \mathrm{min} / 1.73 \mathrm{~m}^{2}\right)$ & $86.0 \pm 35.5$ & $88.9 \pm 37.4$ & $85.6 \pm 36.8^{\ddagger}$ & $84.6 \pm 30.2^{\ddagger}$ & $84.4 \pm 36.2^{\ddagger}$ & $<0.001$ \\
\hline
\end{tabular}

Comparisons were evaluated using the Kruskal wallis test for categorical variables and analysis of variance for continuous variables (post-hoc analysis of least significant difference between the two groups). The first quartile group served as a reference for the comparison between the two groups $A C E i$ angiotensin-converting enzyme inhibitor, ARB angiotensin II receptor blocker, eGFR estimated glomerular filtration rate

${ }^{*} P<0.05 ;{ }^{\dagger} P<0.01 ;{ }^{\ddagger} P<0.001$, compared with the 1 st quartile

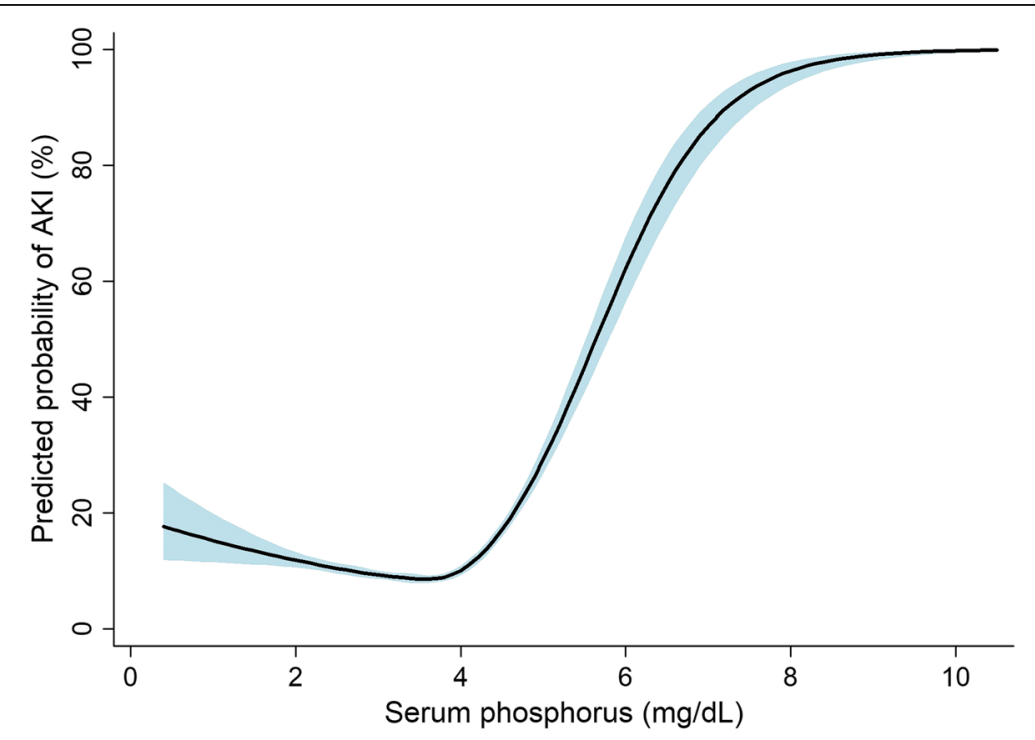

Fig. 1 Non-linear relationship between serum phosphorus and predicted probability of acute kidney injury (AKI). Fitted line and 95\% confidence intervals indicated as solid and shaded areas, respectively 
Table 2 Risk of acute kidney injury according to serum phosphorus level

\begin{tabular}{|c|c|c|c|c|c|c|}
\hline \multirow[b]{2}{*}{ Groups } & \multicolumn{2}{|l|}{ Total } & \multicolumn{2}{|c|}{ eGFR $<60 \mathrm{ml} / \mathrm{min} / 1.73 \mathrm{~m}^{2}$} & \multicolumn{2}{|c|}{$\mathrm{eGFR} \geq 60 \mathrm{ml} / \mathrm{min} / 1.73 \mathrm{~m}^{2}$} \\
\hline & OR $(95 \% \mathrm{Cl})$ & $P$ & OR $(95 \% \mathrm{Cl})$ & $P$ & OR $(95 \% \mathrm{Cl})$ & $P$ \\
\hline Q1 & 1 (reference) & & 1 (reference) & & 1 (reference) & \\
\hline Q2 & $1.16(1.004-1.340)$ & 0.044 & $0.99(0.657-1.480)$ & 0.946 & $1.18(1.012-1.383)$ & 0.034 \\
\hline Q3 & $1.44(1.237-1.684)$ & $<0.001$ & $1.38(0.916-2.077)$ & 0.124 & $1.41(1.194-1.673)$ & $<0.001$ \\
\hline Q4 & $2.80(2.435-3.222)$ & $<0.001$ & $2.64(1.843-3.770)$ & $<0.001$ & $2.60(2.226-3.038)$ & $<0.001$ \\
\hline
\end{tabular}

eGFR estimated glomerular filtration rate, $O R$ odds ratio, $\mathrm{Cl}$ confidence interval

[11]. Hyperphosphatemia was also recently shown to increase the risk of cardiovascular disease in non-CKD patients $[12,13]$. However, most studies of hyperphosphatemia have focused on certain disease subsets rather than considering all hospitalized patients. Furthermore, the relationship between hyperphosphatemia and AKI has not yet been fully established. The present study thus assessed the effects of hyperphosphatemia on the risks of AKI, ESRD, and mortality among a large number of hospitalized patients.

\section{Methods}

\section{Study population}

We retrospectively reviewed data for adult patients (aged $\geq 18$ years) admitted to Seoul National University Bundang Hospital in $2013(n=21,572)$. Patients without measurements of serum phosphorus $(n=575)$ and/or with underlying $\operatorname{ESRD}(n=311)$ were excluded. Consequently, a total of 20,686 patients were included in the present analysis.

\section{Data collection and definitions}

The clinical parameters investigated were age, sex, body mass index, hypertension, diabetes mellitus, history of cardiovascular disease, CKD, and medications (including angiotensin-converting enzyme inhibitors or angiotensin receptor blockers, $\beta$-blockers, calcium channel blockers, and diuretics). Blood parameters including creatinine, hemoglobin, cholesterol, calcium, phosphorus, and albumin were also examined. Estimated glomerular filtration rate (eGFR) was calculated using the CKD Epidemiology Collaboration equation [14].

Primary outcomes were the occurrences of AKI and ESRD after hospital admission. AKI was defined according to the KDIGO guideline [15] as meeting at least one of the following criteria: increase in serum creatinine by $0.3 \mathrm{mg} / \mathrm{dl}$ within $48 \mathrm{~h}$ or increase to 1.5 times baseline, known or presumed to occur within the prior 7 days. Baseline creatinine was defined as the lowest value measured $<90$ days prior to admission. If this value was unavailable, the lowest creatinine value measured between 90 and 180 days before admission was used as the baseline. The events of ESRD, such as dialysis and kidney transplantation, were obtained from the Kidney Renal Registry database of Korea. The additional patient outcome was all-cause mortality following admission. The mortality

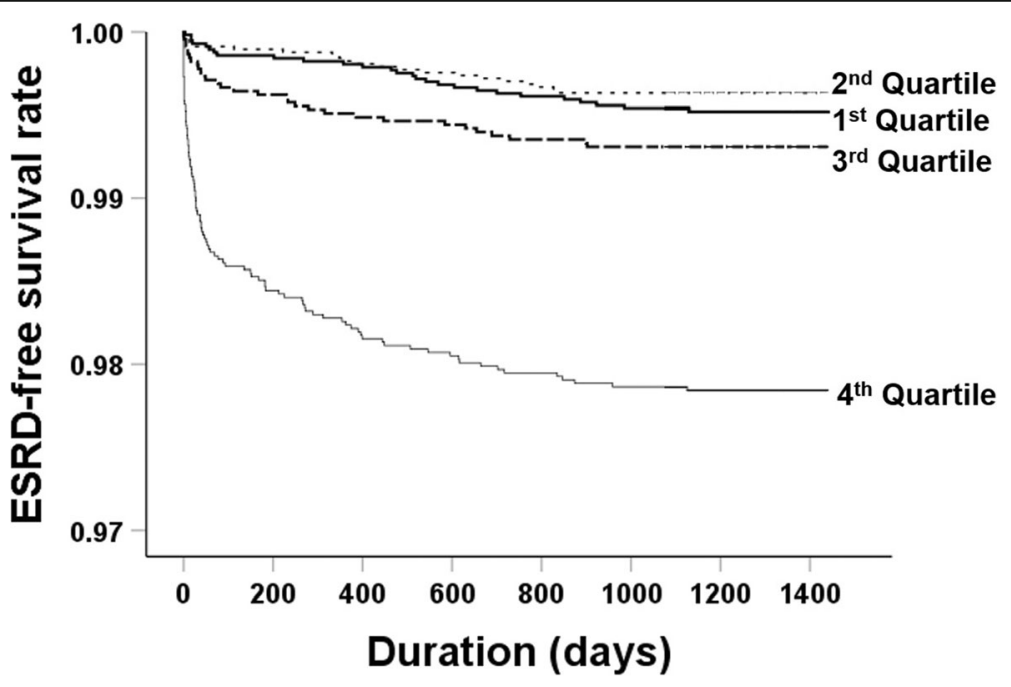

Fig. 2 Kaplan-Meier curves for end-stage renal disease (ESRD) according to quartiles of serum phosphorus 
Table 3 Risk of end-stage renal disease according to serum phosphorus level

\begin{tabular}{|c|c|c|c|c|c|c|}
\hline \multirow[b]{2}{*}{ Groups } & \multicolumn{2}{|l|}{ Total } & \multicolumn{2}{|c|}{$\mathrm{eGFR}<60 \mathrm{ml} / \mathrm{min} / 1.73 \mathrm{~m}^{2}$} & \multicolumn{2}{|c|}{$\mathrm{eGFR} \geq 60 \mathrm{ml} / \mathrm{min} / 1.73 \mathrm{~m}^{2}$} \\
\hline & HR $(95 \% \mathrm{Cl})$ & $P$ & $\mathrm{HR}(95 \% \mathrm{Cl})$ & $P$ & HR $(95 \% \mathrm{Cl})$ & $P$ \\
\hline Q1 & 1 (reference) & & 1 (reference) & & 1 (reference) & \\
\hline Q2 & $0.95(0.609-2.077)$ & 0.871 & $0.99(0.464-2.095)$ & 0.971 & $0.94(0.323-2.736)$ & 0.910 \\
\hline Q3 & $1.45(1.342-4.015)$ & 0.185 & $0.83(0.399-1.712)$ & 0.608 & $2.74(1.110-6.748)$ & 0.029 \\
\hline Q4 & $2.34(1.462-3.750)$ & $<0.001$ & $1.17(0.654-2.100)$ & 0.595 & $5.25(2.361-11.659)$ & $<0.00$ \\
\hline
\end{tabular}

eGFR estimated glomerular filtration rate, $H R$ hazard ratio, $\mathrm{Cl}$ confidence interval

data were obtained from the national database of Statistics Korea. All patients, except patients who were death-censored, were followed up until July 2017.

\section{Statistical analysis}

Statistical analyses were performed using SPSS (version 23.0; IBM Corp., Chicago, IL, USA) and STATA (version 12.0; Stata Corp LP, College Station, TX, USA) softwares. Continuous and categorical variables were expressed as the means \pm standard deviations and the proportions, respectively. Categorical variables were compared by $x^{2}$ tests. Continuous variables were compared by an analysis of variance or a post-hoc analysis of least significant difference, based on the number of comparison groups. Nonlinear relationships were evaluated using a restricted cubic spline analysis. Odds ratios (ORs) with 95\% confidence intervals for the risk of AKI were calculated by a logistic regression, with and without adjustment for the covariates, such as age, sex, body mass index, hypertension, diabetes mellitus, history of cardiovascular disease, medications, eGFR, calcium, hemoglobin, cholesterol, and albumin levels. The relationships between serum phosphorus and ESRD or all-cause mortality were assessed using a Cox proportional hazard ratio (HR) model before and after adjustment for covariates (i.e., AKI plus the above covariates). The relationships were further analyzed after stratification according to baseline kidney function (i.e.,
eGFR $<60 \mathrm{ml} / \mathrm{min} / 1.73 \mathrm{~m}^{2}$ or $\left.\geq 60 \mathrm{ml} / \mathrm{min} / 1.73 \mathrm{~m}^{2}\right) . \quad P$ values $<0.05$ were defined as significant when they were set to two-sided.

\section{Results}

Baseline characteristics

The baseline characteristics of the patients are shown in Table 1 . The study included 20,686 patients $(52.5 \%$ male), with a mean age of 59 years. Patients were split into quartiles according to serum phosphorus levels: first quartile, $<2.9 \mathrm{mg} / \mathrm{dl}$; second quartile, $2.9-3.4 \mathrm{mg} / \mathrm{dl}$; third quartile, $3.5-3.8 \mathrm{mg} / \mathrm{dl}$; and fourth quartile, $>3.8 \mathrm{mg} / \mathrm{dl}$. Patients in the first quartile were older at baseline and included more males compared with the other groups. More patients in the fourth quartile were diagnosed with hypertension, but there was no difference in history of cardiovascular disease among the groups. Patients in the lower quartiles tended to have lower cholesterol and higher eGFR levels. The mean follow-up period was $3.6 \pm 1.2$ years.

\section{Association between serum phosphorus and renal outcome}

AKI occurred in 2321 (11.2\%) patients after hospital admission, with prevalence of $10.6,8.8,9.2$, and $16.6 \%$ in the first to fourth quartiles, respectively. Non-linear relationship analysis demonstrated an exponential relationship between serum phosphorus and the risk of AKI

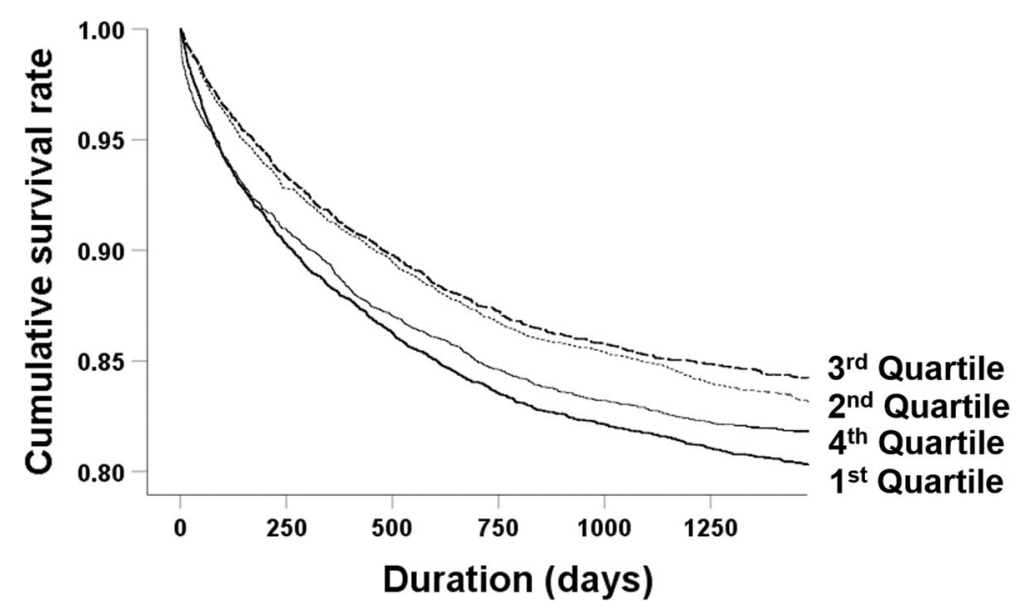

Fig. 3 Kaplan-Meier curves for all-cause mortality according to quartiles of serum phosphorus 
Table 4 Risk of all-cause mortality according to serum phosphorus level

\begin{tabular}{|c|c|c|c|c|c|c|}
\hline \multirow[b]{2}{*}{ Groups } & \multicolumn{2}{|l|}{ Total } & \multicolumn{2}{|c|}{ eGFR $<60 \mathrm{ml} / \mathrm{min} / 1.73 \mathrm{~m}^{2}$} & \multicolumn{2}{|c|}{$\mathrm{eGFR} \geq 60 \mathrm{ml} / \mathrm{min} / 1.73 \mathrm{~m}^{2}$} \\
\hline & $\mathrm{HR}(95 \% \mathrm{Cl})$ & $P$ & $\mathrm{HR}(95 \% \mathrm{Cl})$ & $P$ & HR (95\% Cl) & $P$ \\
\hline Q1 & 1 (reference) & & 1 (reference) & & 1 (reference) & \\
\hline Q2 & $1.10(1.002-1.207)$ & 0.052 & $1.00(0.761-1.309)$ & 0.987 & $1.11(1.008-1.230)$ & 0.034 \\
\hline Q3 & $1.16(1.043-1.281)$ & 0.006 & $1.28(0.976-1.691)$ & 0.075 & $1.14(1.019-1.272)$ & 0.022 \\
\hline Q4 & $1.35(1.221-1.486)$ & $<0.001$ & $1.37(1.064-1.770)$ & 0.015 & 1.34 (1.199-1.487) & $<0.001$ \\
\hline
\end{tabular}

(Fig. 1). Logistic regression analysis showed a U-shaped relationship between phosphate and AKI (ORs: 0.82 $[0.720-0.924]$ in the second quartile, $P=0.001 ; 0.85$ [0.744-0.969] in the third quartile, $P=0.015 ; 1.68$ [1.499-1.881] in the fourth quartile, $P<0.001)$. The positive relationship between phosphate level and risk of AKI remained consistent after adjusting for multiple covariates (Table 2), indicating that the trend was not dependent on reduced kidney function.

Sixty-three patients $(0.3 \%)$ progressed to ESRD status based on kidney function during the follow-up period. The prevalence of ESRD were $0.2,0.1,0.3$, and $0.8 \%$ in the first to fourth quartile groups, respectively. Kaplan-Meier curves for ESRD-free survival rates indicated the highest risk of ESRD in the fourth quartile group (Fig. 2). The HR for the risk of ESRD was 2.34 (1.462-3.750) in the fourth quartile group compared with the first quartile group (Table 3). The HR for ESRD remained higher in the fourth compared with the first quartile group after adjusting for multiple covariates, but this trend was only significant in patients with an eGFR $>60 \mathrm{ml} / \mathrm{min} / 1.73 \mathrm{~m}^{2}$.

As a sensitivity analysis, we divided patients into three groups such as low $(<2.5 \mathrm{mg} / \mathrm{dl})$, normal $(2.5-4.5 \mathrm{mg} / \mathrm{dl})$, and high phosphorus $(>4.5 \mathrm{mg} / \mathrm{dl})$ groups, based on the reference range. Nevertheless, the risks of AKI and ESRD were higher in high phosphorus group than in the normal group, wherein adjusted OR and HR were 6.12 (5.1877.209) $(P<0.001)$ and $1.91(1.311-2.777)(P=0.001)$, respectively. The low group was not associated with the risk of AKI or ESRD (PS $>0.05)$.

\section{Association between phosphorus and mortality}

The all-cause mortality rates were 19.8, 16.9, 15.7, and $18.3 \%$ in the first to fourth quartile groups, respectively, and the Kaplan-Meier survival curves showed similar trends (Fig. 3). Univariate analysis showed that the HRs for mortality were lower in the second and third quartile groups $(0.83$ [0.761-0.904], $P<0.001$ and 0.77 [0.7020.848], $P<0.001$, respectively) compared with the first quartile group. The mortality rates did not differ between the first and fourth quartile groups. However, the mortality risk tended to be higher in the higher quartiles compared with the first quartile group after adjusting for multiple covariates (Table 4). Subgroup analysis revealed positive correlations between serum phosphorus level and risk of mortality in both CKD and non-CKD groups. Although a sensitivity analysis was performed, the high phosphorus group, and not the low phosphorus group, had a higher risk of mortality than the normal group with adjusted HR of $1.54(1.357-1.755)(P<0.001)$.

\section{Discussion}

Hyperphosphatemia has received considerable attention in the field of CKD - mineral and bone disorder (CKDMBD) because of its association with cardiovascular morbidity and mortality $[3,6,16]$. Even upper-normal serum phosphate levels could exacerbate the status of CKD, potentially leading to ESRD [17]. Based on these features, this study addressed the relationships between hyperphosphatemia and the risks of AKI, ESRD, and mortality among hospitalized patients, and showed that hyperphosphatemia was significantly associated to poorer renal outcomes, irrespective of baseline kidney function.

In addition to patients with CKD-MBD, some studies have examined the relationship between serum phosphorus and morbidity or mortality, particularly in critically ill patients. Patients admitted to the emergency department with serum phosphorus levels $>4.5 \mathrm{mg} / \mathrm{dl}$ showed high 28-day in-hospital mortality [18]. Furthermore, higher time-weighted phosphorus levels (i.e., area under the curve divided by total time between first and last phosphorus levels) were related to mortality risk in patients with mechanical ventilation [19]. Hyperphosphatemia was also shown to affect the risk of mortality in patients undergoing continuous renal replacement therapy [20]. However, the relevance of hyperphosphatemia among heterogeneous patients admitted to the hospital remains unclear. Furthermore, AKI and ESRD have rarely been considered as the primary outcomes in previous studies [21].

In the current study, we examined the relationships between hyperphosphatemia and renal outcomes and mortality in both eGFR $<60 \mathrm{ml} / \mathrm{min} / 1.73 \mathrm{~m}^{2}$ and $\geq 60 \mathrm{ml} / \mathrm{min} /$ $1.73 \mathrm{~m}^{2}$ groups, to highlight the dangers of high phosphorus levels irrespective of kidney function. Hyperphosphatemia induced calcification of smooth muscle cells in 
an in vitro system [22], linked to phenotypic changes from vascular smooth muscle cells to osteochondrogenic-like cells [22]. Vascular calcification suggests an increased risk of cardiovascular events and mortality in patients with hyperphosphatemia. Some studies also found that high phosphate intake disrupted endothelial function and thus affected maintenance of the glomerular filtration barrier $[17-19,23-25]$. This impaired vasodilatation is known to be dependent on nitric oxide [18, 25]. The Ramipril Efficacy In Nephropathy (REIN) study conducted in patients with non-diabetic chronic nephropathies found that a 1 $\mathrm{mg} / \mathrm{dl}$ increase in serum phosphate level was associated with a $85 \%$ excess risk of progression to $\operatorname{ESRD}[25,26]$, possibly associated with high secretion of fibroblast growth factor 23 [25]. Following docking of fibroblast growth factor, the respective receptor increases the production of angiotensin-converting enzyme, which may in turn activate the renin-angiotensin system, potentially facilitating the onset and progression of kidney damage in high-risk individuals [26]. Hyperphosphatemia also induced inflammation in vascular smooth muscle cells and increased the expression of matrix metalloproteinases II and IX and cathepsin S [9, 27]. These mechanisms may explain the finding that high concentrations of phosphorus affected renal outcomes, as well as mortality.

The strengths of this study included the large number of hospitalized patients analyzed and its lack of focus on critically ill patients or patients with CKD alone. Nevertheless, the study had some limitations. The retrospective design meant that the causality and mechanism could not be determined. However, this did not affect the primary purpose of the study to determine the relationship between serum phosphorus and renal outcomes. Unidentified factors may also have affected or interacted with the present relationships. We did not investigate the cause of death, which also limited our understanding of the underlying mechanisms. Because of relatively small number of patients with CKD, further studies are needed to assess nonsignificant results such as ESRD progression in CKD subset.

\section{Conclusion}

Hyperphosphatemia is associated to the risks of AKI, ESRD, and mortality among hospitalized patients. Accordingly, serum phosphorus monitoring may help to identify patients at high risk of kidney function deterioration or mortality. Further studies are needed to explore the mechanisms underlying the present observations.

\section{Abbreviations}

ACEi: Angiotensin-converting enzyme inhibitor; AKl: Acute kidney injury ARB: Angiotensin II receptor blocker; CKD: Chronic kidney disease; CKDMBD: CKD-mineral and bone disorder; eGFR: Estimated glomerular filtration rate; ESRD: End-stage renal disease; HR: Hazard ratios; OR: Odds ratios

\section{Acknowledgments}

None.

\section{Authors' contributions}

HM: Concept and design of study. Analysis and interpretation of data. Drafting and critical revision of the article. HJC, KYN, KWJ and YSK: Critical revision of the article. SK and SSH: Concept and design of study. Interpretation of data. Critical revision of the article. Responsible for the integrity of the data acquired, its analysis and interpretation. All authors read and approved the final manuscript.

\section{Funding}

This work was supported by the Basic Science Research Program through the National Research Foundation of Korea (NRF) funded by the Ministry of Education (NRF-2017R1D1A1B03031642 to S.S. Han) and the grant from the NRF (2017R1A2B4005251 to S. Kim), which had no role in the study design, data collection, analysis, interpretation, or writing of the manuscript.

\section{Availability of data and materials}

The datasets used and analyzed during the current study are available from the corresponding author on reasonable request.

\section{Ethics approval and consent to participate}

The study protocol complied with the ethical principles of the Declaration of Helsinki and received full approval from the institutional review boards of Seoul National University Bundang Hospital (no. B-1603/340-117). Under this approval, informed consent was waived.

Consent for publication

Not applicable.

Competing interests

The authors declare that they have no competing interests.

\section{Author details}

${ }^{1}$ Department of Internal Medicine, Seoul National University College of Medicine, 103 Daehakro, Jongno-gu, Seoul 03080, Korea. '2Department of Internal Medicine, Seoul National University Bundang Hospital, 82, Gumi-ro 173beon-gil, Bundang-gu, Seongnam-si, Gyeonggi-do 13620, Korea.

Received: 12 June 2019 Accepted: 6 September 2019

Published online: 18 September 2019

\section{References}

1. Eckardt KU, Coresh J, Devuyst O, Johnson RJ, Kottgen A, Levey AS, et al. Evolving importance of kidney disease: from subspecialty to global health burden. Lancet. 2013;382(9887):158-69.

2. Chronic Kidney Disease Prognosis C, Matsushita K, van der Velde M, Astor BC, Woodward M, Levey AS, et al. Association of estimated glomerular filtration rate and albuminuria with all-cause and cardiovascular mortality in general population cohorts: a collaborative meta-analysis. Lancet. 2010; 375(9731):2073-81.

3. Palmer SC, Hayen A, Macaskill P, Pellegrini F, Craig JC, Elder GJ, et al. Serum levels of phosphorus, parathyroid hormone, and calcium and risks of death and cardiovascular disease in individuals with chronic kidney disease: a systematic review and meta-analysis. Jama. 2011;305(11):1119-27.

4. Heung M, Chawla LS. Predicting progression to chronic kidney disease after recovery from acute kidney injury. Curr Opin Nephrol Hypertens. 2012;21(6):628-34.

5. Basile DP, Bonventre JV, Mehta R, Nangaku M, Unwin R, Rosner MH, et al. Progression after AKI: understanding maladaptive repair processes to predict and identify therapeutic treatments. J Am Soc Nephrol. 2016;27(3):687-97.

6. Kalantar-Zadeh K, Kuwae N, Regidor DL, Kovesdy CP, Kilpatrick RD, Shinaberger CS, et al. Survival predictability of time-varying indicators of bone disease in maintenance hemodialysis patients. Kidney Int. 2006;70(4):771-80

7. Shaman AM, Kowalski SR. Hyperphosphatemia Management in Patients with chronic kidney disease. S Saudi Pharm J. 2016;24(4):494-505. 
8. Moon JYLH, Lee SH, Lee TW, Ihm CG, Jo YI, Han SW, Shin SG. Hyperphosphatemia is associated with patency loss of arteriovenous fistula after 1 year of hemodialysis. Kidney Res Clin Pract. 2015;34(1):41-6.

9. Foley RN, Collins AJ, Herzog CA, Ishani A, Kalra PA. Serum phosphorus levels associate with coronary atherosclerosis in young adults. J Am Soc Nephrol. 2009;20(2):397-404.

10. Da J, Xie X, Wolf M, Disthabanchong S, Wang J, Zha Y, et al. Serum phosphorus and progression of CKD and mortality: a meta-analysis of cohort studies. Am J Kidney Dis. 2015;66(2):258-65.

11. Ketteler M, Block GA, Evenepoel P, Fukagawa M, Herzog CA, McCann L, et al. Diagnosis, evaluation, prevention, and treatment of chronic kidney disease-mineral and bone disorder: synopsis of the kidney disease: improving global outcomes 2017 clinical practice guideline update. Ann Intern Med. 2018;168(6):422-30.

12. Mohammad J, Scanni R, Bestmann L, Hulter HN, Krapf R. A controlled increase in dietary phosphate elevates BP in healthy human subjects. J Am Soc Nephrol. 2018;29(8):2089-98.

13. Tonelli M, Sacks F, Pfeffer M, Gao Z, Curhan G. Relation between serum phosphate level and cardiovascular event rate in people with coronary disease. Circulation. 2005;112(17):2627-33.

14. Levey AS, Stevens LA, Schmid CH, Zhang YL, Castro AF 3rd, Feldman HI, et al. A new equation to estimate glomerular filtration rate. Ann Intern Med. 2009;150(9):604-12.

15. Kidney Disease Improving global outcomes (KDIGO) acute kidney injury work group. KDIGO clinical practice guideline for acute kidney injury. Kidney Int Suppl. 2012;2:1-138.

16. Kestenbaum B, Sampson JN, Rudser KD, Patterson DJ, Seliger SL, Young B, et al. Serum phosphate levels and mortality risk among people with chronic kidney disease. J J Am Soc Nephrol. 2005;16(2):520-8.

17. Chang WX, Xu N, Kumagai T, Shiraishi T, Kikuyama T, Omizo H, et al. The impact of Normal range of serum phosphorus on the incidence of endstage renal disease by a propensity score analysis. PLoS One. 2016:11(4):e0154469.

18. Haider DG, Lindner G, Wolzt M, Ahmad SS, Sauter T, Leichtle AB, et al. Hyperphosphatemia is an independent risk factor for mortality in critically ill patients: results from a cross-sectional study. PLoS One. 2015:10(8):e0133426

19. Miller CJ, Doepker BA, Springer AN, Exline MC, Phillips G, Murphy CV. Impact of serum phosphate in mechanically ventilated patients with severe Sepsis and septic shock. J Intensive Care Med. 2018. [Epub ahead of print].

20. Jung SY, Kwon J, Park S, Jhee JH, Yun HR, Kim H, et al. Phosphate is a potential biomarker of disease severity and predicts adverse outcomes in acute kidney injury patients undergoing continuous renal replacement therapy. PLoS One. 2018;13(2):e0191290.

21. Thongprayoon C, Cheungpasitporn W, Mao MA, Sakhuja A, Erickson SB. Admission hyperphosphatemia increases the risk of acute kidney injury in hospitalized patients. J Nephrol. 2018;31(2):241-7.

22. Al-Aly Z. Phosphate, oxidative stress, and nuclear factor-kappaB activation in vascular calcification. Kidney Int. 2011;79(10):1044-7.

23. Foley RN, Parfrey PS, Sarnak MJ. Clinical epidemiology of cardiovascular disease in chronic renal disease. Am J Kidney Dis. 1998;32(5 Suppl 3):S112-9.

24. Coresh J, Selvin E, Stevens LA, Manzi J, Kusek JW, Eggers P, et al. Prevalence of chronic kidney disease in the United States. Jama. 2007;298(17):2038-47.

25. Jung SY, Kim H, Park S, Jhee JH, Yun HR, Kim H, et al. Electrolyte and mineral disturbances in septic acute kidney injury patients undergoing continuous renal replacement therapy. Medicine (Baltimore). 2016;95(36):e4542.

26. Shuto E, Taketani Y, Tanaka R, Harada N, Isshiki M, Sato M, et al. Dietary phosphorus acutely impairs endothelial function. J Am Soc Nephrol. 2009:20(7):1504-12

27. Foley RN, Collins AJ, Ishani A, Kalra PA. Calcium-phosphate levels and cardiovascular disease in community-dwelling adults: the atherosclerosis risk in communities (ARIC) study. Am Heart J. 2008;156(3):556-63.

\section{Publisher's Note}

Springer Nature remains neutral with regard to jurisdictional claims in published maps and institutional affiliations.

\section{Ready to submit your research? Choose BMC and benefit from:}

- fast, convenient online submission

- thorough peer review by experienced researchers in your field

- rapid publication on acceptance

- support for research data, including large and complex data types

- gold Open Access which fosters wider collaboration and increased citations

- maximum visibility for your research: over $100 \mathrm{M}$ website views per year

At BMC, research is always in progress.

Learn more biomedcentral.com/submissions 